\title{
Beneficial effects of food supplements based on hydrolyzed collagen for skin care (Review)
}

\author{
MIHAELA-ADI LUPU ${ }^{1 *}$, GRATIELA GRADISTEANU PIRCALABIORU ${ }^{1,2 *}$, MARIANA-CARMEN CHIFIRIUC ${ }^{2 *}$, \\ RADU ALBULESCU ${ }^{3,4 *}$ and CRISTIANA TANASE ${ }^{3,5^{*}}$ \\ ${ }^{1}$ SC Sanimed International Impex SRL, 087040 Bucharest; ${ }^{2}$ Research Institute of University of Bucharest (ICUB), \\ 050098 Bucharest; ${ }^{3}$ Biochemistry-Proteomics Department, Victor Babes National Institute of Pathology, \\ 050096 Bucharest; ${ }^{4}$ National Institute for Chemical-Pharmaceutical R\&D, 061323 Bucharest; \\ ${ }^{5}$ Titu Maiorescu University, Faculty of Medicine, 004051 Bucharest, Romania
}

Received October 2, 2019 ; Accepted November 4, 2019

DOI: $10.3892 /$ etm.2019.8342

\begin{abstract}
Ageing is a complex, multi-step process which involves, among others loss of collagen and elastin. Collagen is found in large amounts in the body, especially in the dermis layer. These fibers provide the skin's normal strength, hydration and mechanical properties. Collagen is largely available, as it can be extracted from many animal sources, it can be easily absorbed upon topical administration, hence it is largely used in the cosmetic and pharmaceutical industry for the treatment of premature aging. Bioactive peptides, such as collagen hydrolyzate, are among the most used ingredients for the development of nutraceuticals - food or food ingredients that have defined physiological effects. Numerous studies have demonstrated that peptides resulted from ingestion of hydrolysate collagen and detected in the blood stream have chemotactic properties for skin fibroblasts, helping the skin restoration process. The purpose of this minireview is to present an update on the use of hydrolyzed collagen for skin care.
\end{abstract}

\section{Contents}

1. Introduction

2. Skin ageing - natural occurrence and external triggers33.

3. Sources of collagen peptides

4. Clinical evidence for the beneficial roles of collagen based products for skin care

5. Conclusions

Correspondence to: Professor Cristiana Tanase, BiochemistryProteomics Department, Victor Babes National Institute of Pathology, 99-101 Splaiul Independentei, 050096 Bucharest, Romania

E-mail: bioch@vbabes.ro

${ }^{*}$ Contributed equally

Key words: hydrolyzed collagen, wrinkles, skin, peptide, nutraceuticals

\section{Introduction}

The presence of aging is noticeable in the second decade of life and involves numerous and important changes. Although at the beginning the changes are hardly observable, towards the third decade, important structural and functional changes occur. The skin is a protection system of the body against undesired influences from the external environment (1) having multiple key roles in the sensitivity and protection against physical, chemical and biological aggressors of the human body (2). Due to its large exposure to environmental factors, skin suffers alterations which affect not only this aspect, but ultimately human health conditions (3). This is one of the reasons for which food, cosmetic and pharmaceutical industry are preoccupied with developing novel and improved products to prevent, delay or minimize the signs of ageing and to protect and heal the skin (4).

Nutraceuticals ('nutrition' + 'pharmaceutical') are foods, food ingredients or pharmaceutical/cosmetic products with defined physiological effects (5), but without adverse effects, administered with the purpose to improve health status (6). Due to population growth and diversified food requirements, the consumption of nutraceuticals has increased. Nutraceutical products obtained from plants contain antioxidants, polyunsaturated fatty acids, as well as pre and probiotics. Recently the treatment of collagen deficiency has been treated with bioactive peptides obtained by enzymatic hydrolysis of food proteins. Bioactive peptides, such as collagen hydrolyzate, are among the most used ingredients for the development of nutraceuticals. Collagen represents $\sim 30 \%$ of the body's protein mass and plays an important role in the structure of different tissue types, giving rigidity and integrity to the bones and skin. Collagen fiber has a triple helical structure composed of $\alpha$ chains. Type I collagen is found in mammals and is made up of two $\alpha 1(\mathrm{I})$ and one $\alpha 2(\mathrm{I})$ chains. The skin contains type I and III collagen and the cartilage, type II and III collagen. Collagen fibers confer tensile strength to these tissues. Hydrolyzed collagen is rich in amino acids such as glycine and proline, and after digestion it accumulates in the cartilage or skin and helps maintain stability or regeneration (7). 
Extracellular matrix is mainly composed of collagen proteoglycans. Resistance, molecular filtration, and skin hydration are determined by proteoglycans that also influence cell behavior or cell-matrix interactions. Collagen proteoglycans, which are an important source of cytokines and growth factors, may undergo changes in their expression or structure, which can significantly influence tissue homeostasis (8).

Because collagen and elastin deposits decrease with age, especially due to sun exposure, for the affected areas the cosmetic industry tries to find solutions to improve the appearance of the skin of the face and neck (9). Collagen is an important ingredient of pharmaceutical or food products and acts on connective tissues of skin, tendons, ligaments, and teeth. Collagen peptides are used as dietary supplements in malnutrition or other degenerative diseases to restore bone density. The beneficial effect of collagen peptides on skin elasticity, such as reducing wrinkles or increasing collagen deposition in the dermis, has also been demonstrated in various clinical studies (Table I) (10-15). For this, in order to act in the deep layers of the skin, hydrolyzed collagen must enter the bloodstream, crossing the intestinal barrier (16).

\section{Skin ageing - natural occurrence and external triggers}

Epidermis, formed by proliferative basal cells, and the dermis, formed by keratinocytes, represent the main components of the skin. Dermal fibroblasts produce elastin and collagen type I and III, along with other extracellular matrix proteins (17). Because the dermis through the blood vessels provides important nutrients to the skin and provides structural support to the epidermis, it is necessary to maintain the structure of the dermal layer for proper functioning of the skin cells. Skin ageing can be due to natural processes occurred, intensified or accumulated in time (chronological, intrinsic or natural ageing) or upon solar radiation exposure (extrinsic, photo-ageing). Changes in the dermal layer of the skin, alteration and modifications of the extracellular matrix, as well as increased inflammatory markers and decreased blood flow lead to aging skin (18-20).

The ageing process enhances the cumulative exposure to harmful stimuli such as hemodynamic stress, oxidized lipids, and is linked to impaired angiogenesis and endothelial dysfunction (21). Dermal structure may be affected by natural aging and aged fibroblasts synthesize less collagen. Ultraviolet radiation generates reactive oxygen species that activate matrix metalloproteinases, influencing collagen production through neocolagenesis, leading to a change in the ratio between type I and III of collagen. This results in breakdown of the extracellular matrix and photo aging of the skin (1). Due to the reduction of the collagen amount in the skin and the occurrence of the elastosis phenomenon that causes the disorganized accumulation of elastin proteins in the dermis, dermal atrophy occurs and the skin appears aged (22). The elastosis process occurs especially on the areas of the body exposed to solar radiation. As a consequence of this phenomenon, the activity of the fibroblasts decreases and the mechanical tension is reduced which leads to the degradation of the existing collagen fibers. Due to the increased degree of collagen breakdown in the dermis and the decrease of its synthesis, fine lines appear (1).
The dermis is altered in smokers, and chronic stress acting on the circadian cortisol/corticosterone rhythm alters collagen synthesis and degradation. As a consequence of sun exposure, aging skin becomes drier, has laxity and wrinkles. During the ageing process, wrinkles deepen and skin laxity increases (16).

\section{Sources of collagen peptides}

Gelatin formation results from the irreversible denaturation of the collagen molecules. To stop this denaturation process, a chemical or thermal treatment can be applied. Heat treatment of collagen denaturation is used both in beauty techniques, in medical techniques such as orthopedics, plastic surgery, dental or ophthalmological treatments, but also in the pharmaceutical or food industry. Gelatin is commonly used in the food industry due to the different bioactivities of collagen peptides, especially high biocompatibility and bioavailability (23).

Researchers are actively trying to find new sources of collagen. The hydrolyzed collagen and gelatin currently used are obtained from porcine or bovine type I collagen. Unlike gelatin, hydrolyzed collagen is more suitable for digestion because it dissolves in water or brine and is well absorbed. It has been shown that the age of the animal influences the degree of solubility of collagen, the collagenous tissue of the older animals being harder to solubilize than that obtained from a young animal. Numerous techniques have been developed for obtaining macromolecules based on collagen, and these techniques take into account the source of collagen and its degree of solubilization (24). Good quality gelatin is extracted from the bovine bone, whose peptides act on bone metabolism, being useful in the treatment of osteoarthritis, acting on bone metabolism and inhibiting bone loss. Due to the occurrence of bovine spongiform encephalopathy, the use of this type of gelatin is limited and other sources of collagen are needed. Collagen can be extracted from both animal and vegetable sources, algae and marine organisms, including fish $(3,25)$.

In pharmaceutical, cosmetic and food industries, the use of collagen of marine origin is preferred (26). Collagen and other bioactive substances can be extracted from marine organisms. Among the marine organisms from which collagen is extracted are invertebrates such as jellyfish, sponges, sea urchin, octopus, but also vertebrates including cod, salmon and marine mammals. Unlike collagen of animal origin, collagen obtained from marine sources is more easily absorbed, has low molecular weight and is preferable to industry due to low inflammatory reactions and low number of contaminants (27). Marine collagen is similar in terms of biocompatibility and amino acid content to that of animals of porcine or bovine origin. Also from marine organisms, type I collagen is abundant. Regenerative medicine focuses mainly on tissue engineering, for the replacement or restoration of damaged tissues. Tissue engineering also uses biomaterials, cells and biochemical factors. The most suitable biomaterial for tissue engineering is collagen which allows both cell migration and extracellular matrix-cell interaction, which results in tissue regeneration (26).

In the cosmetic industry, marine collagen is successfully used for the treatment of wounds, burns and ulcers but also for antimicrobial protection, preventing the loss of moisture and heat from the injured tissue (26). 
Table I. Collagen oral supplements in clinical trials.

\begin{tabular}{|c|c|c|c|}
\hline Product & Type of product & Therapeutic effect & Authors/Refs. \\
\hline $\begin{array}{l}\text { VERISOL }^{\circledR} \\
(\text { GELITA AG) }\end{array}$ & $\begin{array}{l}\text { Bioactive collagen peptides (BCP)-collagen } \\
\text { peptides from porcine skin type I collagen }\end{array}$ & $\begin{array}{l}\text { Decrease in the degree of cellulite } \\
\text { and reduced skin waviness }\end{array}$ & Schunck et al (10) \\
\hline $\begin{array}{l}\text { VERISOL }^{\circledR} \\
(\text { GELITA AG) }\end{array}$ & Bioactive I collagen & Increase nail growth & Hexsel et al (11) \\
\hline Nutraceuticals & $\begin{array}{l}\text { Marine collagen peptides (MCPs) - fish skin } \\
\text { MCPs combined with plant-derived } \\
\text { skin-targeting antioxidants (AO) } \\
\text { (coenzyme } \mathrm{Q}_{10}+\text { grape-skin extract + luteolin } \\
+ \text { selenium) }\end{array}$ & $\begin{array}{l}\text { Improve skin elasticity, sebum } \\
\text { production, and dermal } \\
\text { ultrasonic markers }\end{array}$ & De Luca et al (12) \\
\hline Oral supplement & $\begin{array}{l}\text { Content (per tablet): marine protein }(105 \mathrm{mg}), \\
\text { vitamin C }(27 \mathrm{mg}) \text {, grape seed extract }(13.75 \mathrm{mg}) \text {, } \\
\text { zinc }(2 \mathrm{mg}) \text {, and tomato extract }(14.38 \mathrm{mg})\end{array}$ & Improve skin aging in men & Costa et al (13) \\
\hline Marine collagen & Fish collagen hydrolysates $(\mathrm{FCH})$ & Anti-aging effect & Je et al (14) \\
\hline $\begin{array}{l}\text { BioCell Collagen }^{\circledR} \\
\text { (BCC; BioCell } \\
\text { Technology, LLC } \\
\text { Newport Beach, CA, } \\
\text { USA) }\end{array}$ & $\begin{array}{l}\text { Chicken sternal articular cartilage (hydrolyzed } \\
\text { collagen type II and low molecular-weight } \\
\text { hyaluronic acid and chondroitin sulfate) }\end{array}$ & $\begin{array}{l}\text { Reduce skin dryness } \\
\text { and wrinkles }\end{array}$ & $\begin{array}{l}\text { Schwartz and } \\
\text { Park (15) }\end{array}$ \\
\hline
\end{tabular}

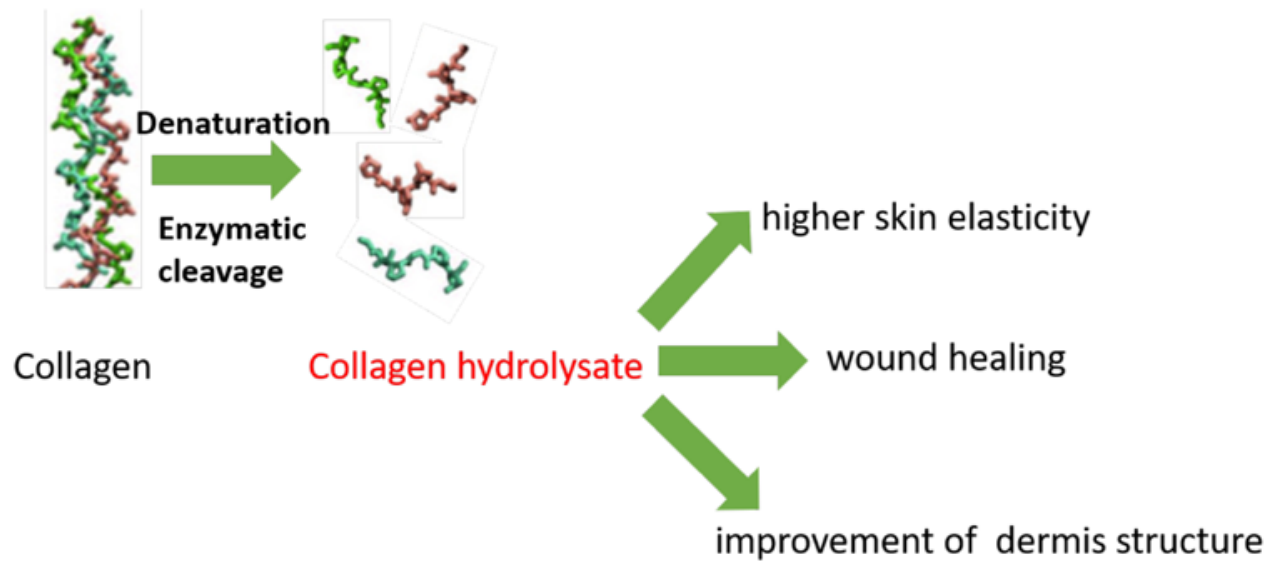

Figure 1. Skin health benefits of collagen hydrolysates.

Because there are important sources of marine collagen, and the peptides obtained from this collagen have the ability to pass intact into the bloodstream after gastrointestinal digestion, but also due to the ability of these biopeptides to help heal wounds, it is preferable to use this type of collagen in industry. The only limitation is the probability of contamination with heavy metals (27-29).

\section{Clinical evidence for the beneficial roles of collagen based products for skin care}

Hydrolyzed collagen has long been used in food supplements and pharmaceutical industry because many clinical studies have shown benefits, such as bioavailability, rapid absorption in the digestive tract, passage into the bloodstream as small peptides and accumulation in the skin $96 \mathrm{~h}$ after ingestion.
After ingestion of hydrolyzed collagen, proline and hydroxyproline were found in the bloodstream. With low molecular weight and rapid absorption, collagen peptides are distributed in different tissues, such as skin, where these peptides have demonstrated their efficacy and benefit (Fig. 1).

Numerous in vitro studies have focused on the antioxidant activity of collagen peptides demonstrating that blood peptides from ingestion of hydrolysate collagen have chemotactic properties for skin fibroblasts, leading to migration and proliferation of murine fibroblasts $(30,31)$. Fibroblasts activated by hydrolysate collagen cause the production of collagen, hyaluronic acid and elastin. After ingestion, collagen peptides can remain in the dermis for up to 14 days, ensuring skin protection from sunlight and improving moisture retention while helping to repair endogenous elastin and collagen fibers. Following oral administration of bovine hydrolyzed collagen, 
improvement in the aging of the skin was observed along with an increase in the amount of cutaneous collagen and a change in the ratio of collagen from type I to type II (32). Currently, there are numerous commercial products in the field of food supplements or cosmetic products based on collagen and the above clinical studies.

The Pure Gold Collagen ${ }^{\circledR}$ Food Supplement (Minerva Research Labs Ltd.) is a type I hydrolyzed collagen product extracted from fish containing low molecular weight hyaluronic acid to which several vitamins and minerals are added. Borumand and Sibilla showed in a study that if one consumes $50 \mathrm{ml}$ of Pure Gold Collagen daily for 60 days, the dryness of the skin is reduced, the wrinkles and the nasolabial depth are reduced, and after 12 weeks the skin becomes firmer and increases collagen density (33).

Another commercial product is the BioCell Collagen ${ }^{\circledR}$ food supplement composed of type II hydrolyzed collagen, low molecular weight hyaluronic acid and chondroitin sulfate. In a study conducted by Schwartz and Park (15) in 2012 on 26 healthy women who were given $1 \mathrm{~g}$ of BioCell Collagen ${ }^{\circledR}$ daily, the beneficial effect of this product was demonstrated after a 12-week administration period, namely, a significant reduction in skin dryness and wrinkles. Laboratory investigations also showed an increase in hemoglobin and collagen content in the dermis after BioCell Collagen ${ }^{\circledR}$ administration for 6 weeks. BioCell Collagen ${ }^{\circledR}$ (BCC; BioCell Technology, LLC) is a hydrolyzed collagen extracted from chicken cartilage and each capsule contains $300 \mathrm{mg}$ of hydrolyzed collagen, $100 \mathrm{mg}$ of depolymerized chondroitin sulfate and $50 \mathrm{mg}$ of acid hyaluronic. Subjects received two capsules per day for 12 weeks, monitoring the appearance of the skin of the face, facial wrinkles, tone, texture and hyperpigmentation of the skin. At the final evaluation, it was found that the wrinkles were significantly reduced and the skin dryness decreased. Besides the visible changes of the skin, physiological changes in the metabolism of the molecules in the dermal and epidermal layers were also noted.

The administration of hydrolyzed collagen of animal origin (chicken, pig) to human subjects after $12 \mathrm{~h}$ of fasting showed an increase in the amount of hydroxyproline in the blood with a maximum at $2 \mathrm{~h}$ after digestion, then decreasing at $4 \mathrm{~h}$ after digestion (15).

The VERISOL ${ }^{\circledR}$ product (GELITA AG) which is type I porcine hydrolyzed collagen has been tested on 69 healthy women. Women received 2.5-5 g of hydrolyzed collagen daily. At 4 weeks after administration the group of older women showed a significant increase in skin elasticity which was maintained after the treatment was stopped. Hydrolyzed collagen had a beneficial effect on skin elasticity at the end of the treatment period regardless of the dose administered (2.5 or $5 \mathrm{~g})(18)$.

Studies have also been carried out on nutritional products based on collagen peptides and antioxidants, demonstrating an increase in skin elasticity after 90 days of consumption. Bioactive peptides in the dermis have double action: on the one hand free amino acids help to form collagen fibers and on the other hand these peptides bind to receptors on the fibroblast membrane stimulating their proliferation and implicitly the production of hyaluronic acid, collagen and elastin (23).
Many scientific studies provide evidence that supplementation with vitamins from group $\mathrm{C}$ or $\mathrm{E}$ can improve skin appearance because nutrients may have specific properties, which attract water molecules thus improving hydration in the skin, scavenge free radicals or reduce inflammation. Vitamin C is also an essential co-factor in the biosynthesis of collagen. Another study tested a hydrolyzed collagen product in a group of 18 menopausal women. The tested product also contained vitamin $\mathrm{C}$ and hyaluronic acid. After oral consumption for 9 weeks of this product there was an improvement in the appearance of the skin and a significant reduction in the depth of wrinkles in the tested subjects. At the same time, the degree of hydration, the loss of water and the elasticity of the skin were observed. In addition, it was shown that daily oral supplementation with $1 \mathrm{~g}$ of this type of hydrolyzed collagen for up to 12 weeks led to significant reduction of wrinkles and improvement of skin elasticity and in the degree of skin dryness (33).

Campos et al (34) performed a study on a product composed of a combination of amino acids (hydrolyzed collagen peptides: glycine, proline and hydroxyproline), supplemented with hydrosoluble vitamins (A and C) and lyposoluble vitamins (E) and zinc. They tested the effectiveness of the treatment by biophysical techniques and imaging of the skin. The study enrolled 60 healthy women who each received daily for three months $10 \mathrm{~g}$ of test product in the form of water soluble oral powder. At the end of the study, there was a visible reduction of wrinkles and large pores, a good elasticity of the skin and a better structure of the dermis. The conclusion of the study was that a hydrolyzed collagen product supplemented with vitamins and zinc is much more effective in improving the aging conditions of the skin. It was concluded that by combining the three types of amino acids (glycine, proline and hydroxyproline) with vitamins and zinc that have antioxidant effect, the protection against reactive oxygen species is ensured. These reactive oxygen species are responsible for oxidative stress, which are closely related to both the inflammatory process and the collagen synthesis process $(35,36)$. So far, the beneficial effects of hydrolyzed collagen have been demonstrated on a number of skin conditions. The beneficial effects of hydrolyzed collagen have been extensively analyzed for a series of skin conditions (37), but further studies are need in order to address their application for other dermatological ailments (for instance the use of a topical remedy in case of the hyperpigmented, velvety, hyperkeratotic plaques found on the skin of patients with Aacanthosis nigricans) (38).

\section{Conclusions}

It is known that the aging process of the skin is closely related to the molecular metabolism and the modifications of the extracellular matrix in the dermis, resulting in the modification of the structure and functionality of the collagen fibers, elastin and hyaluronic acid. Clinical manifestations of this process include increased laxity, fragility, dryness of the skin and the appearance of wrinkles. It has been proven that daily consumption of hydrolyzed collagen in different doses, from different sources can bring many benefits for the human body from relieving joint pain to improving skin health. Hydrolyzed collagen can be isolated from different sources including bovine, porcine skin, marine organisms, chicken skin and fish cartilage. It can be associated with vitamins and other types 
of nutrients. Due to the BSE outbreak in bovines, for cosmetic industry, collagen of marine origin is being considered a highly attractive source. Intake of supplements containing hydrolyzed collagen is associated with many host beneficial effects including the slowing of skin ageing.

\section{Acknowledgements}

We would like to thank Dr Ana-Maria Enciu for her help during the revision of the manuscript.

\section{Funding}

This study was supported by grant COP A 1.2.3., ID: P_40_197/2016 (Ctr. 52/2016/ component project 259) and Ministry of Research and Innovation in Romania, under Program 1 - The Improvement of the National System of Research and Development, Subprogram 1.2 - Institutional Excellence - Projects of Excellence Funding in RDI, Contract No. 7PFE/16.10.2018.

\section{Availability of data and materials}

The datasets used and/or analyzed during the current study are available from the corresponding author on reasonable request.

\section{Authors' contributions}

MAL, GGP, MCC, RA, CT: equally contributed to data gathering, manuscript drafting, critical revision of the manuscript for important intellectual content. All authors read and approved the final manuscript.

\section{Ethics approval and consent to participate}

Not applicable.

\section{Patient consent for publication}

Not applicable.

\section{Competing interests}

The authors declare that they have no competing interests.

\section{References}

1. Madison KC: Barrier function of the skin: 'la raison d'être' of the epidermis. J Invest Dermatol 121: 231-241, 2003.

2. Proksch E, Brandner JM and Jensen JM: The skin: An indispensable barrier. Exp Dermatol 17: 1063-1072, 2008.

3. Jensen JM and Proksch E: The skin's barrier. G Ital Dermatol Venereol 144: 689-700, 2009.

4. Pérez-Sánchez A, Barrajón-Catalán E, Herranz-López M and Micol V: Nutraceuticals for skin care: A comprehensive review of human clinical studies. Nutrients 10: 403, 2018.

5. Donno D, Mellano MG, Cerutti AK and Beccaro GL: Biomolecules and natural medicine preparations: Analysis of new sources of bioactive compounds from Ribes and Rubus spp. Buds. Pharmaceuticals (Basel) 9: 7, 2016.

6. Ilie MA, Caruntu C, Tampa M, Georgescu SR, Matei C, Negrei C, Ion RM, Constantin C, Neagu M and Boda D: Capsaicin Physicochemical properties, cutaneous reactions and potential applications in painful and inflammatory conditions. Exp Ther Med 18: 916-925, 2019.
7. Porfírio E and Fanaro GB: Collagen supplementation as a complementary therapy for the prevention and treatment of osteoporosis and osteoarthritis: A systematic review. Rev Bras Geriatr Gerontol 19: 153-164, 2016.

8. Tzanakakis GN, Neagu M, Tsatsakis AM and Nikitovic D: Proteoglycans and immunobiology of cancer - therapeutic implications. Front Immunol 10: 875, 2019.

9. Hincu M, Surdu O, Leon A and Mateescu G: Cellular and molecular alterations in skin submitted to ultraviolet radiations. Rom Biotechnol Lett Suppl 15: 62-69, 2010.

10. Schunck M, Zague V, Oesser S and Proksch E: Dietary supplementation with specific collagen peptides has a body mass index-dependent beneficial effect on cellulite morphology. J Med Food 18: 1340-1348, 2015.

11. Hexsel D, Zague V, Schunck M, Siega C, Camozzato FO and Oesser S: Oral supplementation with specific bioactive collagen peptides improves nail growth and reduces symptoms of brittle nails. J Cosmet Dermatol 16: 520-526, 2017.

12. De Luca C1, Mikhal'chik EV, Suprun MV, Papacharalambous M, Truhanov A and Korkina LG: Skin antiageing and systemic redox effects of supplementation with marine collagen peptides and plant-derived antioxidants: A single-blind case-control clinical study. Oxid Med Cell Longev 2016: 4389410, 2016.

13. Costa A,Pegas Pereira ES, Assumpção EC, Calixto Dos Santos FB, Ota FS, de Oliveira Pereira M, Fidelis MC, Fávaro R, Barros Langen SS, Favaro de Arruda LH, et al: Assessment of clinical effects and safety of an oral supplement based on marine protein, vitamin $\mathrm{C}$, grape seed extract, zinc, and tomato extract in the improvement of visible signs of skin aging in men. Clin Cosmet Investig Dermatol 8: 319-328, 2015.

14. Je HJ, Han YK, Lee HG and Bae IY: Anti-aging potential of fish collagen hydrolysates subjected to simulated gastrointestinal digestion and Caco-2 cell permeation. J Appl Biol Chem 62: 101-107, 2019.

15. Schwartz SR and Park J: Ingestion of BioCell Collagen $\left({ }^{\circledR}\right)$, a novel hydrolyzed chicken sternal cartilage extract; enhanced blood microcirculation and reduced facial aging signs. Clin Interv Aging 7: 267-273, 2012.

16. Kohl E, Steinbauer J, Landthaler M and Szeimies RM: Skin ageing. J Eur Acad Dermatol Venereol 25: 873-884, 2011.

17. Cole MA, Quan T, Voorhees JJ and Fisher GJ: Extracellular matrix regulation of fibroblast function: Redefining our perspective on skin aging. J Cell Commun Signal 12: 35-43, 2018.

18. Proksch E, Segger D, Degwert J, Schunck M, Zague V and Oesser S: Oral supplementation of specific collagen peptides has beneficial effects on human skin physiology: A double-blind, placebo-controlled study. Skin Pharmacol Physiol 27: 47-55, 2014.

19. Caravia L, Dudau M, Gherghiceanu M, Tanase C and Enciu AM: Could caveolae be acting as warnings of mitochondrial ageing? Mech Ageing Dev 146-148: 81-87, 2015.

20. Ilie MA, Caruntu C, Lixandru D, Tampa M, Georgescu SR, Constantin MM, Constantin C, Neagu M, Zurac SA and Boda D: In vivo confocal laser scanning microscopy imaging of skin inflammation: Clinical applications and research directions. Exp Ther Med 17: 1004-1011, 2019.

21. Tanase C, Popescu ID, Enciu AM, Gheorghisan-Galateanu AA, Codrici E, Mihai S, Albulescu L, Necula L and Albulescu R: Angiogenesis in cutaneous T-cell lymphoma - proteomic approaches. Oncol Lett 17: 4060-4067, 2019.

22. Uitto J: Understanding premature skin aging. N Engl J Med 337: 1463-1465, 1997.

23. Genovese L, Corbo A and Sibilla S: An insight into the changes in skin texture and properties following dietary intervention with a nutricosmeceutical containing a blend of collagen bioactive peptides and antioxidants. Skin Pharmacol Physiol 30: 146-158, 2017.

24. Tanase CP, Albulescu R and Neagu M: Application of 3D hydrogel microarrays in molecular diagnostics: Advantages and limitations. Expert Rev Mol Diagn 11: 461-464, 2011.

25. Chirita M, Oniscu C, Vlad DM and Veisa G: Contributions at the biomaterials base development. The collagen hydrolyse from sheep skin, for biomedical applications. Rom Biotechnol Lett 6: 511-520, 2001.

26. Silva TH, Moreira-Silva J, Marques AL, Domingues A, Bayon Y and Reis RL: Marine origin collagens and its potential applications. Mar Drugs 12: 5881-5901, 2014.

27. Vollmer DL, West VA and Lephart ED: Enhancing skin health: By oral administration of natural compounds and minerals with implications to the dermal microbiome. Int J Mol Sci 19: 3059, 2018. 
28. Felician FF, Xia C, Qi $\mathrm{W}$ and $\mathrm{Xu} \mathrm{H}$ : Collagen from marine biological sources and medical applications. Chem Biodivers 15: e1700557, 2018.

29. Meghea A, Murariu A, Tanase C and Codorean E: Heavy metals contamination of commercial fish foodstuff - potential health risks on human consumers. EEMJ 8: 233-236, 2009.

30. Shigemura Y, Iwai K, Morimatsu F, Iwamoto T, Mori T, Oda C, Taira T, Park EY, Nakamura Y and Sato K: Effect of Prolyl-hydroxyproline (Pro-Hyp), a food-derived collagen peptide in human blood, on growth of fibroblasts from mouse skin. J Agric Food Chem 57: 444-449, 2009.

31. Ohara H, Ichikawa S, Matsumoto H, Akiyama M, Fujimoto N, Kobayashi $\mathrm{T}$ and Tajima S: Collagen-derived dipeptide, proline-hydroxyproline, stimulates cell proliferation and hyaluronic acid synthesis in cultured human dermal fibroblasts. J Dermatol 37: 330-338, 2010.

32. Song H, Zhang S, Zhang L and Li B: Effect of orally administered collagen peptides from bovine bone on skin aging in chronologically aged mice. Nutrients 9: 1209, 2017.

33. Borumand M and Sibilla S: Effects of a nutritional supplement containing collagen peptides on skin elasticity, hydration and wrinkles. J Medical Nutrition Nutraceuticals 4: 47-53, 2015.
34. Campos PMBG, Melo MO, Calixto LS and Fossa MM: An oral supplementation based on hydrolyzed collagen and vitamins improves skin elasticity and dermis echogenicity: A clinical placebo-controlled study. Clin Pharmacol Biopharm 4: 1000142, 2015.

35. Siwik DA, Pagano PJ and Colucci WS: Oxidative stress regulates collagen synthesis and matrix metalloproteinase activity in cardiac fibroblasts. Am J Physiol Cell Physiol 280: C53-C60, 2001.

36. Filip-Ciubotaru F, Manciuc C, Stoleriu G and Foia L: NADPH oxidase: Structure and activation mecanisms (review). Note I. Rev Med Chir Soc Med Nat Iasi 120: 29-33, 2016.

37. Das L, Bhaumik E, Raychaudhuri U and Chakraborty R: Role of nutraceuticals in human health. J Food Sci Technol 49: 173-183, 2012.

38. Popa ML, Popa AC, Tanase C and Gheorghisan-Galateanu AA: Acanthosis nigricans: To be or not to be afraid. Oncol Lett 17: 4133-4138, 2019.

This work is licensed under a Creative Commons Attribution-NonCommercial-NoDerivatives 4.0 International (CC BY-NC-ND 4.0) License. 